Págs. 167-185

\title{
Culturas de escola e excelência: entre a integração de todos e a distinção dos melhores ${ }^{1}$
}

\author{
School Culture and Excellence: Amidst Integration of Each Person \\ and the Distinction of the Best
}

\author{
Leonor L. Torres ${ }^{2}$
}

\section{Resumo}

Sem perder de vista a multidimensionalidade inerente aos percursos escolares, este texto procura refletir sobre a importância dos fatores organizacionais na construção dos resultados académicos. O enfoque incide sobre as dimensões intra-escolares, designadamente os efeitos da cultura de escola (nas suas diferentes facetas) e dos processos de liderança sobre a socialização dos estudantes. Optando por uma linha de pesquisa reflexiva, procura-se compreender os processos de construção de habitus (no sentido de Bourdieu) e os sistemas de disposições (na ótica de Lahire) estruturadores da cultura organizacional de escola. Do ponto de vista metodológico recorre-se a dados recolhidos no âmbito de um estudo multicasos realizado em quatro escolas públicas do ensino secundário localizadas em diferentes regiões de Portugal. De entre o extenso corpus de informação compilada, mobilizam-se os dados provenientes da análise documental, dos inquéritos por questionário, das entrevistas individuais e dos focus group realizados aos alunos e das entrevistas realizadas a professores, gestores pedagógicos e Diretores. Os resultados apontam para as seguintes tendências gerais: i) relevância do efeito-escola no desenvolvimento de figurinos organizacionais, na definição de estilos e padrões de liderança e no modo como o programa de socialização institucional condiciona as representações dos alunos; ii) interiorização da cultura de escola, ao ponto de a maioria dos alunos atribuírem centralidade aos fatores organizacionais na construção da excelência académica; iii) centralidade da instituição escolar no desenvolvimento de disposições face à escola e aparente secundarização da influência da família nos processos de escolarização.

\section{Palavras chave}

Cultura de escola, estilos de liderança, excelência académica.

\section{Abstract}

Without disregarding the inherent multidimensionality of school pathways, the present lecture seeks to reflect on the importance of organizational aspects in the development of academic results. The main focus is within-school dimensions, namely the effects of school culture (in its different dimensions) and leadership processes on the socialization of students. Adopting a reflective research approach, it is sought the comprehension of the construction of habitus (as employed by Bourdieu) and the structural systems of dispositions (according to Lahire) of organizational school culture. From a methodological standpoint, data previously collected from four Portuguese secondary schools of different regions by means of documental analysis, surveys, focus groups and individual interviews conducted with the students (being the latter conducted with teachers, pedagogical managers and school directors as well) points to the following general trends: i) relevance of the school-effect in the development of organizational models, the definition of patterns and styles of leadership and in the conditioning of the student's representations the by program of institutional socialization; ii) Internalization of the school culture, to the point of students attributing centrality to the organizational factors in the construction of their own academic excellence; iii) Importance of the school institution in the development of dispositions towards school and the apparent secondary relevance of the family in the conditioning of the schooling processes.

\section{Keywords}

School culture, leadership style, academic excellence. 


\section{Introdução}

A vasta literatura produzida internacionalmente sobre a problemática da cultura organizacional tornou evidente a sua inscrição em diferentes paradigmas teórico-metodológicos. Por força das circunstâncias políticas e ideológicas que vêm marcando a agenda internacional, o movimento gerencialista da cultura (cf. Torres, 2004) foi ganhando vigor e projeção, não só pelo facto de os seus pressupostos estarem alinhados com as preocupações mais imediatas das organizações, mas também pela forma como se transformou num instrumento de legitimação dos postulados da nova gestão pública. As dimensões culturais passaram a estar na ordem do dia, uma vez que delas dependem os processos de mudança que se pretendem instituir nos mais diversos contextos.

No campo da educação este fenómeno foi ainda mais expressivo, tendo desencadeado inúmeras pesquisas que procuraram comprovar a relação entre a cultura e os processos de melhoria, mudança e eficácia organizacional (e.g. Hargreaves, 1995; Hargreaves, Boyle, Harris, 2014). Porém, embora esta linha de abordagem se afirme como a mais mediática, não esgota as potencialidades da análise cultural na compreensão dos processos de escolarização e, em particular, da construção da excelência escolar. Pelo contrário, à expansão e mediatização deste movimento teórico não tem correspondido um efetivo desenvolvimento das suas potencialidades heurísticas, tal como assertivamente afirmou Paul du Gay a propósito dos estudos sobre a «identidade»: «But can something be simulteously expanding its empire and losing its explanatory power?» (du Gay, 2007: 1). Enclausurados em sequencialidades lineares e unidirecionais (princípio e fim, causa e consequência), muitos destes estudos reduzem de tal forma a complexidade do real, que escondem todo um imenso campo de possibilidades de compreensão dos contextos e suas configurações sistémicas. Todavia, convém notar que, mais recentemente, alguns trabalhos desenvolvidos numa linha mais interpretativa e reflexiva contribuíram de forma significativa para o aprofundamento do conhecimento da problemática da cultura e da liderança escolar por referência a vários contextos nacionais (e.g. Sergiovanni, 2004, Barzanò, 2009; Derouet e Normand, Dir., 2014; Lindle, Ed., 2014).

Inscrita nesta linha interpretativa, a abordagem da cultura organizacional privilegia a natureza plural e dinâmica dos processos de construção do simbólico, enfatizando tanto as interdependências quanto as singularidades do fenómeno. Ancorado nestes pressupostos, o presente artigo propõe, num primeiro momento, um modelo de análise que contempla várias faces da cultura, dispostas em rede, para dar conta das múltiplas configurações culturais que cada organização escolar pode apresentar, bem como dos diversos estilos de liderança a elas associados. Sob a inspiração deste modelo teórico, procura-se, num segundo momento, explorar os efeitos da cultura de escola e dos processos de liderança sobre a produção de resultados escolares, recorrendo para o efeito à discussão de dados recolhidos no âmbito de um projeto de investigação coletivo concluído em 2015.

\section{As faces da cultura de escola}

A análise sociológica das dimensões culturais da escola reclama uma abordagem tridimensional: um olhar dirigido às orientações de política educativa (transnacionais e nacionais) que balizam determinado projeto de escolarização, um olhar focado nas especificidades desenvolvidas em cada escola e um olhar atento aos contextos de inserção da escola. A articulação destas três escalas (mega-macro, meso e micro) amplia a visibilidade das diferentes dimensões da cultura de escola que, embora profundamente intrincadas, revelam distintos contornos em cada instituição escolar. A exploração das diferentes faces da cultura permite discernir a categoria analítica mais apropriada a cada situação -cultura escolar, cultura sociocomunitária, cultura 
organizacional escolar e cultura organizacional de escola-, numa tentativa de superar a enorme profusão terminológica que ainda persiste na comunidade científica (Prosser, 1999) e que, inevitavelmente, gera várias desordens conceptuais. Estas categorias abrangem diferentes modos de expressão da cultura, podendo ser encontrados na literatura científica alguns trabalhos paradigmáticos de cada um destes enfoques. Todavia, sendo a escola uma «encruzilhada de culturas» (Pérez Gómez, 1998), na realidade, a cultura da escola não se decompõe em faces separadas e justapostas, pelo contrário, elas interconectam-se no tempo e no espaço. De forma a tornar mais inteligível a presente proposta, expõe-se cada uma das faces em separado, procurando estabelecer uma articulação com os processos de liderança.

Face 1: A cultura escolar e as lideranças sem rosto

Sem entrar diretamente nas controvérsias teóricas que animaram os debates nas últimas décadas (cf. Torres, 2004, 2010), é importante reforçar o princípio de que a cultura é socialmente construída na longa duração e que, no decurso do seu desenvolvimento, é condicionada por diversos fatores internos e externos à instituição. A forma como cada escola em concreto constrói e sedimenta a sua cultura depende, portanto, dos múltiplos contextos em que se insere e da sua trajetória evolutiva. A proposta teórica representada na figura 1 pretende justamente identificar as condições que presidem à construção da cultura. Assim, enquanto o eixo horizontal discrimina os fatores de acordo com a sua localização (interna ou externa à escola), o eixo vertical diferencia o seu grau de formalização (mais ou menos formal). Simplificando a leitura, o cruzamento dos dois eixos no espaço-tempo visibiliza o recorte de quatro cenários culturais, sem que tal signifique a sua insularidade. Pelo contrário, as suas fronteiras apresentam-se fluídas e transitórias, traduzindo o dinamismo próprio dos processos culturais sempre inacabados.

O cenário 1 - cultura escolar, resultante da influência dos fatores externos e formais, constitui a génese fundacional da instituição escolar. No quadro de uma administração centralizada (como a portuguesa), as orientações normativas emanadas do centro exercem um efeito de uniformização sobre o sistema escolar, ao induzirem um padrão de funcionamento institucional que, ao longo do tempo, tende a consolidar uma identidade que se confunde com o próprio projeto de escolarização. A cultura escolar, ou na acepção de Pérez Gomes (1998), a cultura institucional, historicamente instituída espelha os modos dominantes de pensar e fazer a escola, materializados na sua configuração física e arquitetónica e, de modo ainda mais expressivo, na sua configuração política, pedagógica e curricular. Aparentemente imutável no tempo, a cultura escolar sofre, contudo, oscilações consoante as conjunturas sócias históricas e a força que certas medidas de política educativa exercem sobre a sua configuração. $\mathrm{Na}$ atualidade, uma das marcas da cultura escolar reside justamente na orientação para a produção de resultados, exercendo um efeito nivelador ao nível dos (re)arranjos organizacionais, curriculares e pedagógicos (Power \& Whitty, 1999). A presença desta dimensão cultural tende a induzir uma liderança de tipo reverencial, refém das orientações externas e dependente do exercício quotidiano de prestação de contas. O impacto intrusivo da Web, designadamente as plataformas informáticas como ferramentas de controlo (Lima, 2012), modificou e condicionou as práticas profissionais e as próprias prioridades educativas. Em termos concetuais, estaríamos em presença de uma hetero-liderança, uma liderança sem rosto, apenas reproduzindo as diretivas do centro ou as circunstâncias impostas pela comunidade (cenário 2 - cultura sociocomunitária).

Face 2: A cultura sociocomunitária e as lideranças dispersas

Neste segundo cenário, a cultura tende a repercutir as influências do meio social em que está inseri- 
da, seja por via da regulação municipal, seja por via da pressão exercida pelas forças do mercado, no sentido mais vasto. Numa altura em que em Portugal se reforça e contratualiza a delegação de competências do Estado para os municípios, abre-se um novo espaço de condicionamento da vida escolar, agora mais próximo, mas também mais disperso e difuso ao nível dos mecanismos de controlo. A escola passa a ser duplamente regulada - pela administração central e pelas instâncias municipais-, sem que estejam garantidas as condições de articulação entre as diversas intervenções. Neste quadro, a escola vê-se confrontada com a necessidade de integrar as lógicas de desenvolvimento territorial, fazendo uso de diversas estratégias: (re)articulando o seu projeto educativo com as prioridades do projeto educativo municipal, reforçando a sua imagem social na comunidade, como mecanismo de reação a eventuais lógicas de competição local, ou mesmo, fazendo valer a sua especificidade cultural como suporte e sustentação de um projeto de escolarização que se pretende manter e reforçar. Esta faceta da cultura tem sido ainda pouco explorada, podendo vir a constituir no futuro uma interessante linha de pesquisa.

A influência das estruturas locais de base nas dinâmicas de funcionamento da organização escolar coloca a tónica na importância da cultura sociocomunitária balizada pelas atividades sociais e redes locais que ocorrem em determinados espaços-tempo. Inserida neste cluster de atividades e vinculada a padrões locais de interação, a escola desenvolve e reajusta as suas estratégias de atuação, sendo provável o recurso a estilos de liderança que tendem a ser mais ou menos dispersos e transitórios consoante as oscilações políticas e sociais.

\section{Gráfico 1. Processo de construção da cultura de acordo com as diversas faces} FORMAL

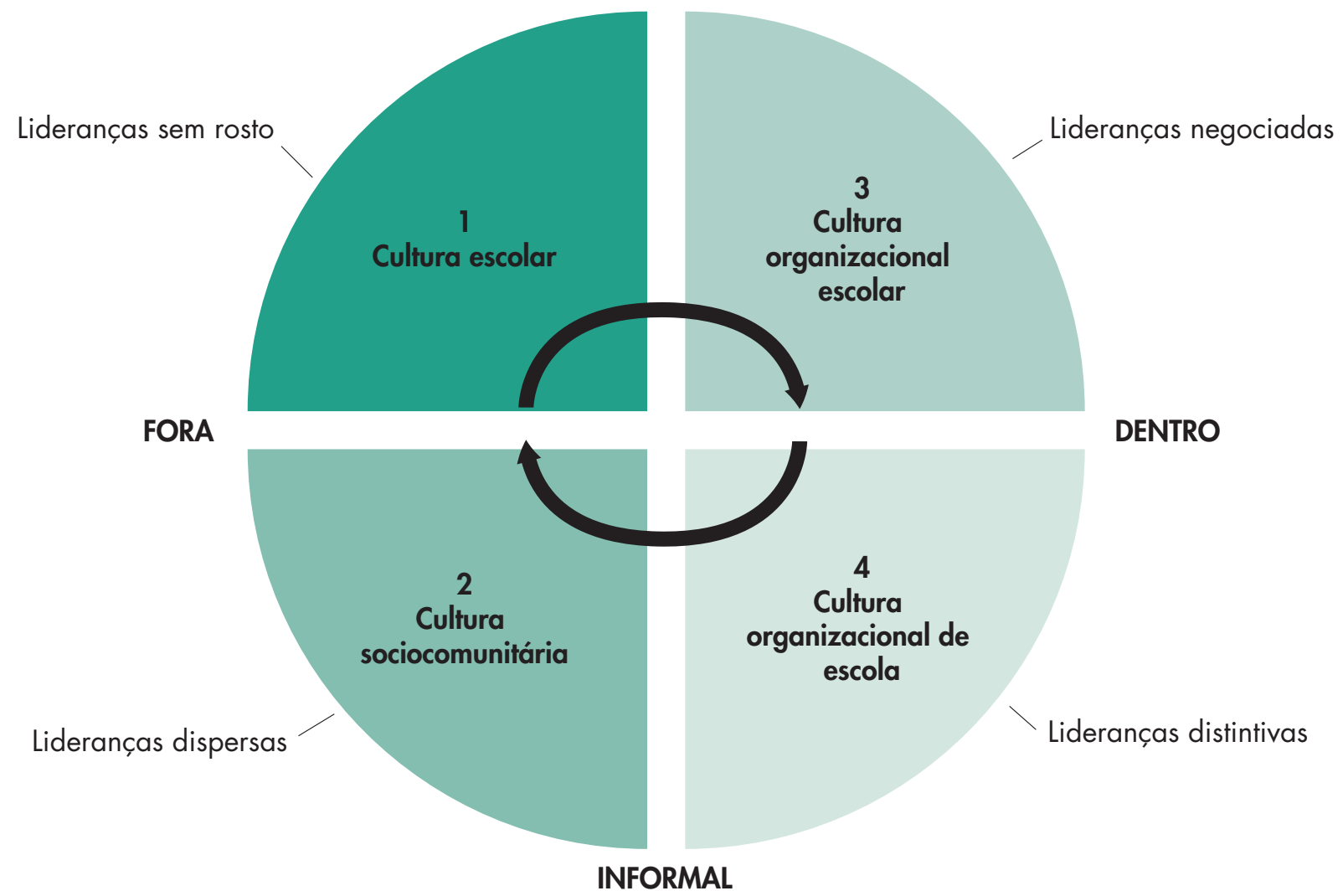


Face 3: A cultura organizacional escolar e as lideranças negociadas

Porém, mais do que reprodutoras de orientações externas, as organizações escolares recriam e reinventam quotidianamente a sua cultura, numa constante dialética entre o fora e o dentro, entre o imposto e o desejado, entre a norma e a ação. Assim é que os dispositivos organizacionais podem ser diferentes em cada escola, em resultado dos distintos modos de apropriação das orientações legais e da sua efetiva concretização. Apesar de as instituições ostentarem, no plano formal, estruturas de gestão similares, tal não significa que as suas dinâmicas, configurações e modos de atuação sejam semelhantes. Pelo contrário, a cultura organizacional escolar, quando olhada a partir de dentro (fatores internos), é essencialmente plural, no duplo sentido: i) inter-escolar, uma vez que cada escola desenvolve uma cultura que lhe é própria e que a diferencia das outras organizações; ii) intra-escolar, na medida em que cada cultura de escola é ela própria plural, pois contempla distintas manifestações culturais (integradoras, diferenciadoras e fragmentadoras -cf. Frost et al., Ed., 1991; Martin, 1992, 2002; Alvesson, 2002. É no decurso da ação e na flecha do tempo que a cultura organizacional escolar ganha forma, ao exigir dos seus atores formas de ação congruentes com as orientações externas. Desta apropriação, nem sempre linear e consensual, podem resultar arranjos organizacionais e formas de fazer e pensar a educação específicas de cada escola - a definição da missão da escola plasmada no projeto educativo, os critérios que presidem à constituição de turmas, as modalidades de avaliação, as pedagogias dominantes, a organização dos espaços-tempo, constituem apenas exemplos de manifestações culturais diferenciadas existentes em cada instituição. Tais manifestações (verbais, visuais, simbólicas e comportamentais) refletem a partilha mais ou menos alargada de um padrão de pressupostos (Schein, 1985), isto é, crenças, ideologias e valores considerados válidos em determinada instituição.

Esta terceira face da cultura remete para uma análise mais interpretativa da vida escolar, focando o olhar na forma como os atores incorporam as normas e como conferem sentido à sua ação quotidiana, designadamente em contextos marcados por inúmeras contingências sociais e profissionais. À luz desta perspetiva, as lideranças tendem a adotar estilos mais híbridos, decorrentes das constantes negociações exigidas pelos múltiplos agentes que povoam o mundo escolar.

Face 4: A cultura organizacional de escola e as lideranças distintivas

A grelha analítica integra uma última face -cultura organizacional de escola, para dar conta do efeito de profundidade da sedimentação cultural ocorrida em determinadas instituições. Este olhar mais circunscrito e contextualizado revela o quanto certas dimensões simbólicas podem perdurar no tempo, ditando padrões de comportamento e instituindo lógicas de trabalho individuais e coletivas, que poderão resultar no desenvolvimento de habitus (Bourdieu, 1997, 2002) e de disposições para agir, pensar e sentir (Lahire, 2003, 2004). Desvela ainda o modo como certos fatores (internos e externos à escola) penetram e canonizam a cultura, mostrando como esta é moldada pelas relações sociais (e.g. Torres, 1997, 2004; Teixeira, 2002). Esta face cultural representa a camada mais profunda e oculta, mas igualmente a mais estruturante da vida organizacional, na medida em que lhe confere uma identidade singular construída na longa duração. É na dimensão temporal que se opera a construção simbólica, que se abre a oportunidade de interagir, partilhar e/ou confrontar valores e visões do mundo e, sobretudo, que se estabilizam os padrões culturais legitimados pelos atores. A temporalidade é, efetivamente, uma condição estruturante e estruturadora da cultura da escola. Neste sentido, a antiguidade da instituição constitui um pilar fundamental do desenvolvimento cultural, um fator revelador do grau (e das possibilidades) de consolidação, diferenciação ou fragmentação da identidade escolar. 
A génese e a natureza da cultura podem ser encontradas na forma como os atores enfrentaram, historicamente, as diversas orientações políticas, criando e recriando referenciais de ação próprios que, independentemente das contingências externas e das lideranças internas, se estabilizaram no tempo como símbolos a preservar. Resultante de processos sócio históricos diferenciados, este reduto cultural apresenta feições distintas em cada escola, podendo exercer um efeito condicionador sobre os processos de liderança, designadamente na definição da missão estratégica da organização escolar. Enformadas por esta ambiência, as lideranças tendem a repercutir o ethos cultural, constituindo em muitos casos a sua expressão mais visível. Ou seja, mais do que reproduzir as orientações externas, o trabalho de liderança opera autorregulações permanentes, de forma a garantir uma articulação entre as demandas externas e as especificidades internas. Deste exercício de mediação cultural resultam perfis de liderança distintivos e singulares, dificilmente integráveis nas tipologias disponíveis na literatura de pendor mais normativista.

\section{Rumo teórico-metodológico}

Tendo como referência o modelo analítico exposto, as organizações escolares desenvolvem culturas distintas, em função do nível de expressão que cada face assume em determinado momento histórico. Interessa, portanto, compreender de que modo as escolas, designadamente as suas lideranças, definem os programas políticos, elegem as prioridades estratégicas e os valores que as sustentam. Por outro lado, importa analisar até que ponto a cultura da escola influi na socialização dos estudantes e na produção de resultados. Estas (e outras) inquietações sustentaram o desenho metodológico de um projeto de investigação desenvolvido entre 2013 e $2015^{3}$, que contemplou a realização de quatro estudos de caso em escolas secundárias públicas do norte do país. No âmbito destes estudos procedeu-se à análise de diversos documentos, à administração de dois inquéritos por questionário a alunos com diferentes níveis de desempenho e à realização de entrevistas individuais e grupais (focus group) a diferentes grupos de alunos.

As quatro escolas estudadas apresentam perfis organizacionais distintos, cujos traços se sintetizam no quadro 1: i) duas escolas relativamente bem posicionadas nos rankings e com a instituição de quadros de excelência e/ou valor (EC1 e EC3); ii) uma escola relativamente bem posicionada nos rankings e sem implementação de quadros de excelência e/ou valor (EC2); uma escola mal posicionada nos rankings, mas em fase de instituição de distinções (EC4). De notar que o estudo-piloto realizado na EC1 representa um caso paradigmático do ponto de vista da assunção dos resultados como linha prioritária da ação política, tendo sido uma das escolas pioneiras em Portugal a recuperar, em 2003, o ritual do quadro da excelência. Formalmente instituído no despacho normativo n. ${ }^{\circ}$ 102/90, de 12 de setembro, o quadro de excelência foi reforçado uns anos mais tarde pelo despacho n. ${ }^{\circ} 13173-\mathrm{C} / 2011$, de 30 de setembro, referente ao «Prémio de Mérito» e, ainda, pelo Estatuto do Aluno do Ensino não-superior (Lei n. ${ }^{\circ}$ 51/2012, de 5 de setembro), no capítulo referente aos direitos do aluno, na alínea d), onde se pode ler que o aluno tem o direito de «ver reconhecidos e valorizados o mérito, a dedicação, a assiduidade e o esforço no trabalho e no desempenho escolar e ser estimulado nesse sentido».

\footnotetext{
3 Trabalho financiado por Fundos Nacionais através da FCT - Fundação para a Ciência e a Tecnologia no âmbito do projeto PTDC/IVC-PEC/4942/2012 do Centro de Investigação em Educação da Universidade do Minho (CIEd), intitulado Entre Mais e Melhor escola: A excelência académica na escola pública portuguesa.
} 
Tabela I. Perfil dos Estudos de Caso

\begin{tabular}{|c|c|c|c|c|c|c|}
\hline & $\begin{array}{c}\text { Tipo } \\
\text { de organização }\end{array}$ & $\begin{array}{l}\text { Localização } \\
\text { (distrito) }\end{array}$ & $\begin{array}{l}\text { Liderança } \\
\text { consecutiva }\end{array}$ & $\begin{array}{l}\text { Contrato } \\
\text { autonomia }\end{array}$ & $\begin{array}{l}\text { Posição nos } \\
\text { rankings (a) }\end{array}$ & $\begin{array}{c}\text { Rituais } \\
\text { de distinção }\end{array}$ \\
\hline \multirow{3}{*}{$\mathrm{ECl}$} & \multirow{3}{*}{ Esc. Secundária não agrupada } & \multirow{3}{*}{ Porto } & \multirow{3}{*}{21} & \multirow{3}{*}{ Sim } & $2012-158 .^{\circ}$ & \multirow{3}{*}{ Quadro de excelência } \\
\hline & & & & & $2013-86 .^{0}$ & \\
\hline & & & & & $2014-86 .^{\circ}$ & \\
\hline \multirow{3}{*}{ EC2 } & \multirow{3}{*}{$\begin{array}{l}\text { Esc. Secundária-sede de } \\
\text { Agrupamento }\end{array}$} & \multirow{3}{*}{ Braga } & \multirow{3}{*}{13} & \multirow{3}{*}{ Não } & $2012-59 .{ }^{\circ}$ & \multirow{3}{*}{ Diplomas de mérito } \\
\hline & & & & & $2013-87 .{ }^{\circ}$ & \\
\hline & & & & & $2014-106 .^{\circ}$ & \\
\hline \multirow{3}{*}{ EC3 } & \multirow{3}{*}{ Esc. Secundária não agrupada } & \multirow{3}{*}{ Porto } & \multirow{3}{*}{16} & \multirow{3}{*}{ Sim } & $2012-88 .{ }^{\circ}$ & \multirow{3}{*}{ Quadro de excelência e valor } \\
\hline & & & & & $2013-s / i$ & \\
\hline & & & & & $2014-170 .^{\circ}$ & \\
\hline \multirow{3}{*}{ EC4 } & \multirow{3}{*}{$\begin{array}{l}\text { Esc. Secundária-sede de } \\
\text { Agrupamento }\end{array}$} & \multirow{3}{*}{ Aveiro } & \multirow{3}{*}{25} & \multirow{3}{*}{ Não } & $2012-230 .^{\circ}$ & \multirow{3}{*}{ Em fase de implementação } \\
\hline & & & & & $2013-41 .^{\circ}$ & \\
\hline & & & & & $2014-519 .{ }^{\circ}$ & \\
\hline
\end{tabular}

Legenda: ( $\left.{ }^{a}\right)$ Rankings elaborados por um jornal diário de expansão nacional; s/i - Sem informação: em 2013 esta escola não foi considerada no ranking.

No intuito de analisar os sentidos da relação cultura-liderança-resultados, incidiu-se a análise nos programas políticos das escolas, vertidos em ações concretas de gestão e liderança e, num momento subsequente, focou-se o olhar nas opiniões dos estudantes sobre a organização escolar e a importância atribuída aos processos de liderança nas suas trajetórias de escolarização.

\section{Os programas político-estratégicos das escolas}

Parte-se do pressuposto de que os programas político-estratégicos das escolas se inscrevem na sua matriz cultural e, nesse sentido, visibilizam a presença mais ou menos acentuada de uma ou mais facetas da cultura. Neste sentido, as opções políticas configuram processos de socialização, impulsionando comportamentos que, por força da sua repetição, podem transformar-se em padrões culturais. Sendo a instituição escolar uma das mais poderosas agências de socialização dos jovens, importa compreender de que forma a sua cultura condiciona o desenvolvimento de aprendizagens e de disposições individuais e coletivas, no sentido proposto por Lahire $(2003$, 2004). Apesar de os trabalhos de Lahire e Bourdieu não se inscreverem de forma imediata no campo dos estudos organizacionais, alguns dos seus contributos revelam-se indispensáveis à compreensão dos mecanismos de produção da cultura organizacional, sobretudo ao nível da camada mais profunda (cultura organizacional de escola). Ao apresentar um esboço de uma teoria da prática, Bourdieu (2002: 163) trabalha o conceito de habitus para se referir ao efeito das estruturas (ou de uma ação organizadora) sobre a produção de «sistemas de disposições duráveis», que geram estratégias que visam enfrentar situações diversas. Por sua vez, Lahire mobiliza os princípios da teoria disposicionalista para a compreensão do ator em ação, alertando para as lógicas multicausais que presidem às práticas, resultantes dos múltiplos contextos de socialização. A experiência socializadora na organização escolar (re)ativa, no tempo, a construção de disposições intra e inter-individuais, que podem revelar-se fundamentais à compreensão dos estilos de gestão e liderança e à sedimentação da cultura organizacional de escola.

Com o propósito de analisar o perfil político das escolas, a figura 2 propõe a ideia de continuum balizado por cenários ideais-tipo, na exata aceção weberiana, por oposição a uma classificação de natureza dicotómica, assente em oposições mutuamente exclusivas. Tal significa que a realidade observada pode situar-se ora mais próxima dos extremos do continuum, configurando perfis de escolas mais democráticas ou mais elitistas, ora situar-se em diferentes lugares ao longo desse mesmo espaço consoante as com- 
binações encontradas nos «reportórios interpretativos» das equipas diretivas a propósito da missão da escola. O cenário 1 dá conta de uma visão meritocrática de escola, apologista da seleção dos alunos e de uma política pedagógica centrada na construção da excelência académica; o cenário 2 inscreve-se numa visão democrática de escola, que privilegia como princípios fundamentais a igualdade e acesso e sucesso e a promoção da inclusão e da participação democrática. O espaço que medeia os dois polos representa as diferentes possibilidades de conciliação entre prioridades educativas observáveis nas organizações escolares.

\section{Gráfico 2. Variantes da missão da escola}

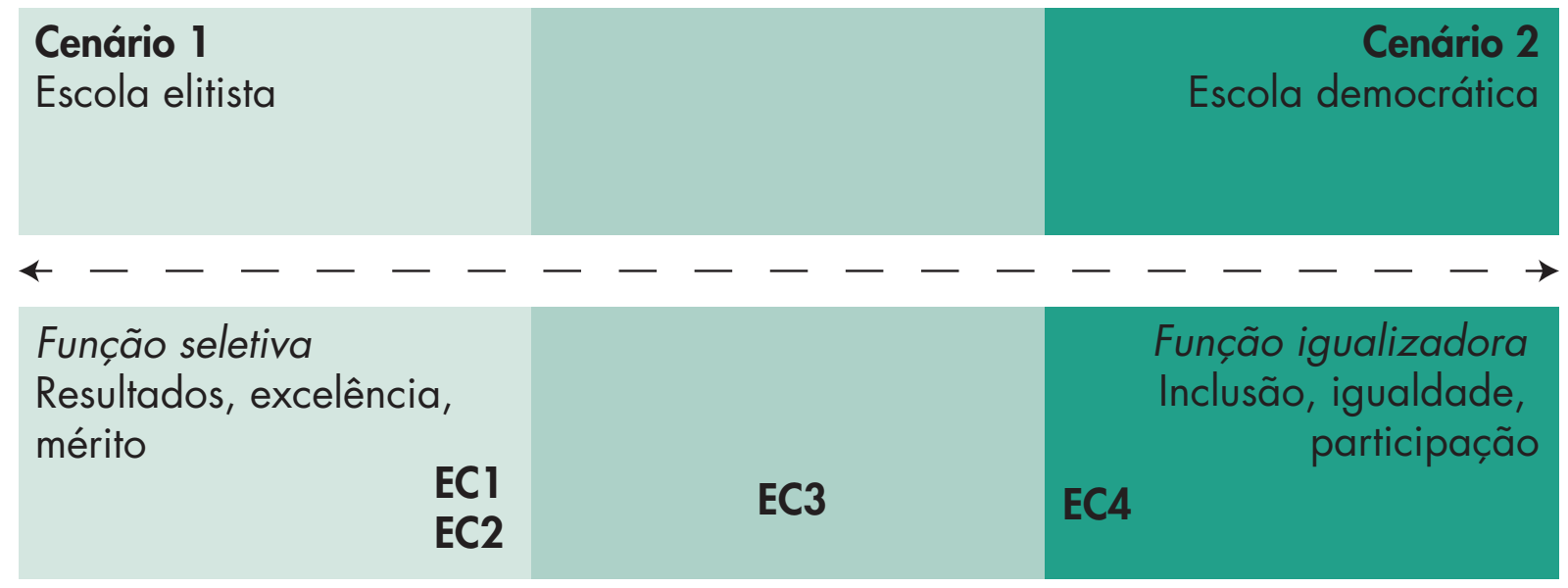

A escola analisada no EC1, herdeira de uma cultura liceal centenária, é uma escola de referência no domínio dos resultados, tendo fundado as suas raízes num ideário de excelência. A estabilidade do corpo docente e das equipas diretivas contribuíram para a preservação de uma identidade socialmente reconhecida, alicerçada numa visão de escola claramente voltada para a preparação dos estudantes para o ensino superior. O compromisso com a qualidade e a excelência dos resultados está explicitamente inscrito nos sucessivos projetos educativos como um referencial da ação, tendo também sustentado os fundamentos das duas candidaturas do Diretor. Para além disso, no segundo contrato de autonomia, firmou-se ainda como um dos objetivos operacionais a necessidade desta instituição escolar «[se] constituir como uma escola de referência a nível nacional, referência na qualidade do serviço educativo que presta e na qualidade nos resultados escolares dos alunos» (cláusula 2. ${ }^{a}$ do Contrato de Autonomia, homologado em 30 de julho de 2013). A assunção destes valores pelos atores que desempenham funções de gestão conduziu, naturalmente, à criação de cenários adequados à promoção da excelência. A recuperação do ritual de distinção dos melhores alunos, através da instituição do quadro de excelência, representa uma estratégia de socialização para a performatividade, com efeitos empiricamente observáveis ao nível da promoção de um clima pedagógico focado nos resultados. Por exemplo, desde o momento em que foi instituído o quadro de excelência, verificou-se um aumento significativo (185\%) do número de alunos distinguidos anualmente. A celebração dos altos desempenhos em cerimónia pública e a sua cuidadosa preparação ao longo do ano parece exercer nos alunos uma pressão constante para a superação de si na escada do sucesso. $O$ culto da excelência e a sua ritualização adquire uma significativa centralidade pedagógica, tornando-se no epicentro da atividade educativa a partir do qual se desencadeia todo um movimento que se alastra e envolve a organização. 
Com um perfil semelhante, a escola estudada no EC2 apresenta como imagem de marca a aposta na qualidade, no rigor e na excelência. Herdeira do ensino industrial e comercial, cujas raízes remontam ao final do século XIX, a escola secundária integrou em 2013 um mega-agrupamento, que se encontra em fase de consolidação institucional. Quer o projeto educativo emergente do agrupamento, quer o plano de intervenção da Diretora, destacam a importância dos princípios da qualidade e da excelência na definição da missão estratégica. Reconhecida na comunidade como uma das melhores escolas da região, uma imagem reforçada pela posição privilegiada ocupada nos rankings e pelo número de alunos colocados anualmente no curso de Medicina, aderiu recentemente ao ritual da distinção dos melhores alunos através de uma celebração pública aberta à comunidade. A estabilidade, a longevidade e a experiência do corpo docente e não docente têm potenciado a consolidação de um ethos de escola sustentado nos valores da excelência.

As evidências empíricas recolhidas permitem-nos situar estas duas escolas (EC1 e EC2) mais próximas do cenário 1 -escola elitista (cf. gráfico 1), não somente pelo facto de os projetos políticos e pedagógicos assumirem uma missão explicitamente focada nos resultados, mas igualmente pela forma como tal orientação desencadeia iniciativas e programas de ação convergentes com tais princípios. A título meramente ilustrativo, as nuvens de palavras apresentadas na figura 3 mostram os termos mais utilizados nos projetos educativos de cada escola. No EC1, as quatro palavras mais repetidas -sigla da escola, alunos comunidade e qualidade- formam um todo coerente quando associado aos significados atribuídos no documento: a primazia dada à identidade da Escola (representada pela sigla) construída na base de um ensino de qualidade fortemente reconhecido e legitimado pela comunidade. Por sua vez, no EC2, a prevalência dos termos educação, agrupamento, avaliação e sucesso, remete para um ideário educativo preocupado com a recente constituição do agrupamento e focado fundamentalmente nos processos de avaliação e no desenvolvimento do sucesso educativo.

\section{Gráfico 3. Palavras mais destacadas nos projetos educativos (EC1 e EC2)}
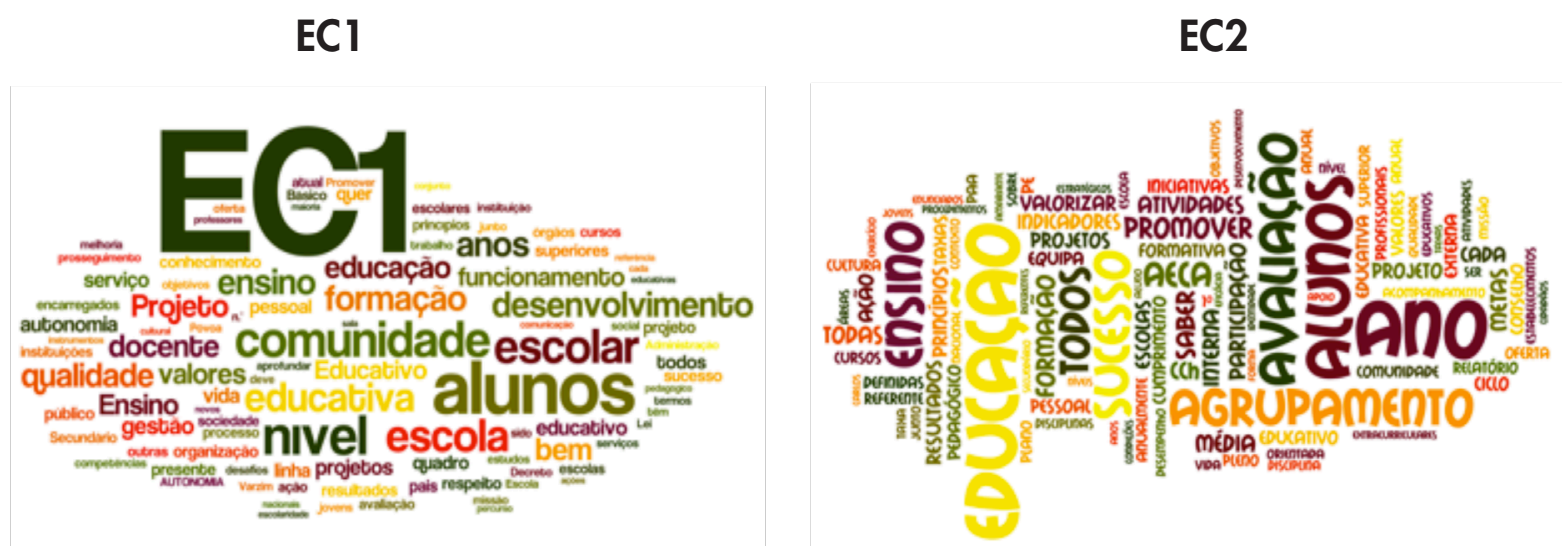

Por sua vez, a escola estudada no EC3, uma instituição não agrupada com menos de 40 anos, tem desenvolvido uma identidade mais voltada para as dimensões democráticas, inclusivas e cidadãs, privilegiando a construção da identidade pessoal e social do aluno em articulação com uma política de qualidade, exigência e responsabilidade. Esta orientação marcadamente humanizadora é visível ao nível das iniciativas e dinâmicas pedagógicas, consideradas como um ponto forte pela equipa de avaliação externa. Contudo, nos últimos anos, denota-se uma preocupação crescente com os resultados académicos e com a promoção da excelência. A distinção dos bons desempenhos a par da premiação dos alunos com com- 
portamentos exemplares, refletida na criação de um quadro de excelência e de um quadro de valor, traduz a tentativa de conciliação entre os princípios democráticos e meritocráticos. Por esta razão situamos esta escola entre os dois polos do continum.

Por fim, a escola analisada no EC4, apresenta um perfil distinto das anteriores, quer do ponto de vista da sua performance ao nível dos resultados, quer no plano da definição das prioridades político-educativas. Escola recentemente agrupada e ocupando instalações antigas, convive diariamente com a forte concorrência das instituições de ensino secundário vizinhas, que foram objeto de requalificação da Parque Escolar. Preocupada com a perda de alunos e com os resultados escolares, tem investido prioritariamente na promoção de boas condições de trabalho, sobretudo na criação de um clima de trabalho e de estudo e, paralelamente, na projeção de uma imagem de qualidade. As preocupações com a qualidade dos resultados conduziram à criação, pela primeira vez em 2014, de mecanismos de distinção dos melhores alunos. A especificidade do público escolar e os princípios norteadores da ação diretiva parecem configurar uma escola mais próxima do cenário 2 -escola democrática, embora seja já evidente a existência de um programa de ação pedagógica focado na melhoria dos resultados.

As nuvens de palavras obtidas a partir da análise dos projetos educativos destas duas escolas expressam bem os sentidos das suas visões estratégicas: na EC3, uma preocupação com a construção de uma Escola associada à ideia de desenvolvimento integral e, em paralelo, a centralidade conferida à aprendizagem e aos processos de avaliação enquanto meios para alcançar o sucesso; na EC4, destaque para a ideia de agrupamento enquanto espaço de inclusão de todos os alunos e, simultaneamente, para a necessidade de trabalhar a imagem da escola junto da comunidade, uma estratégia de gestão voltada para a captação de alunos.

\section{Gráfico 3. Palavras mais destacadas nos projetos educativos (EC3 e EC4) \\ EC3 \\ EC4}

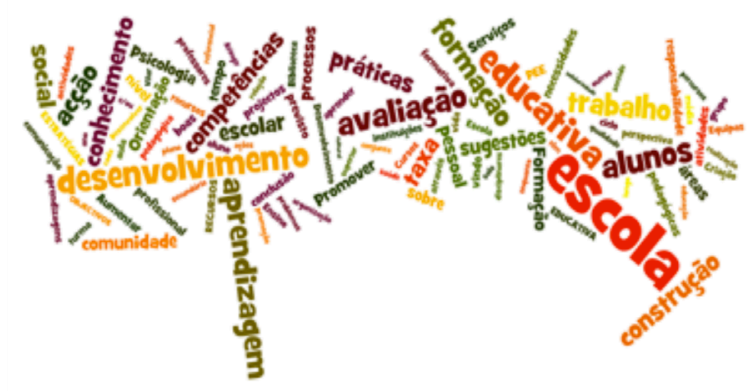

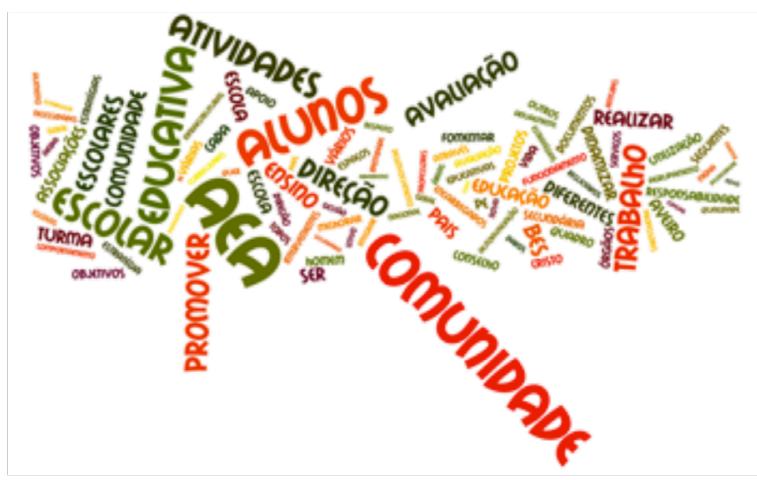

Perante a evidência de diferentes missões de escola que enquadram e norteiam as atuações das lideranças formais, e no intuito de compreender os efeitos destes processos sobre a socialização dos alunos, procurou-se indagar, num segundo momento, os modos como estes jovens percecionam a escola e conferem sentido à sua trajetória escolar.

\section{A escola na perspetiva dos alunos}

A análise dos programas políticos das quatro escolas estudadas pôs em evidência diferentes faces da cultura associadas a distintos perfis de liderança, uns mais focados na produção de resultados, outros mais atentos às dimensões da inclusão e outros, ainda, mais comprometidos com a conciliação de ambas as 
prioridades. Estas variações refletem, certamente, as distintas disposições dos Diretores face à organização escolar, constituídas no tempo por referência aos vários contextos de interação (professores, famílias, comunidade, administração central, entre outros) e estruturantes da própria cultura organizacional de escola.

Estas disposições organizacionais, ora mais performativas, ora mais inclusivas, quando traduzidas em orientações e práticas de gestão concretas, adquirem uma força significativa no desenvolvimento do processo de socialização dos estudantes. Embora estes atores estejam submetidos a uma pluralidade de tempos e espaços de socialização (a família, os amigos, os contextos culturais, desportivos e associativos, entre outros), a organização escolar ocupa um lugar central no seu processo de desenvolvimento, não só pelo tempo de permanência na instituição, como pela forma intensiva, constante e regular que caracteriza o processo de escolarização. Neste sentido, a natureza dos programas político-pedagógicos e a forma como as lideranças formais os operacionalizam em cada escola configuram pilares fundamentais no processo de incorporação de disposições pelos estudantes.

Um conjunto articulado de questões orientou o rumo teórico-metodológico da pesquisa nas quatro escolas: qual a importância atribuída pelos estudantes aos aspetos organizacionais na promoção do seu desempenho? Como perspetivam a liderança e a sua influência nos resultados escolares? Até que ponto os alunos bem-sucedidos se revêm no modelo de liderança da escola?

De entre um extenso corpus de dados, selecionou-se a informação recolhida através de um inquérito por questionário administrado a dois grupos de alunos: ao universo de alunos distinguidos no quadro de excelência das escolas, com classificações finais iguais ou superiores a 18 valores $(n=200)$; e a uma amostra estratificada proporcional de alunos «não excelentes» ( $n=822$ ), que inclui todos aqueles que não atingiram o patamar dos 18 valores. Apenas no EC4 se optou por não inquirir os alunos com desempenhos de excelência, devido ao facto de o número de casos ser residual (cf. tabela 2). Estes dados serão ainda confrontados com os depoimentos dos alunos recolhidos em contexto de entrevista (individual e focus group) realizada a 40 estudantes com diferentes níveis de desempenho.

\section{Tabela II. Inquéritos por questionário administrados nos quatro estudos de caso}

\begin{tabular}{lccccccccc} 
& \multicolumn{3}{c}{ ALUNOS EXCELENTES } & \multicolumn{3}{c}{ ALUNOS NÃO EXCELENTES } & \multicolumn{3}{c}{ TOTAL } \\
\hline & Universo & Inquiridos & $\%$ a & Amostra & Inquiridos & $\%$ & Amostra & Inquiridos & $\%$ b \\
\hline $\begin{array}{l}\text { Estudo de caso } \\
1 \text { (ECI) }\end{array}$ & 68 & 62 & 91,2 & 315 & 298 & 94,6 & 383 & 360 & 94,0 \\
\hline $\begin{array}{l}\text { Estudo de caso } \\
2 \text { (EC2) }\end{array}$ & 97 & 93 & 95,9 & 380 & 333 & 87,6 & 477 & 426 & 89,3 \\
\hline $\begin{array}{l}\text { Estudo de caso } \\
3 \text { (EC3) }\end{array}$ & 132 & 45 & 34,1 & 161 & 82 & 50,9 & 293 & 127 & 43,3 \\
\hline $\begin{array}{l}\text { Estudo de caso } \\
4 \text { (EC4) }\end{array}$ & - & - & - & 132 & 109 & 82,6 & 132 & 109 & 82,6 \\
\hline \begin{tabular}{l} 
Total \\
\hline
\end{tabular} & 297 & 200 & 67,3 & 988 & 822 & 83,2 & 1285 & 1022 & 79,5 \\
\hline
\end{tabular}

Legenda: a Percentagem de resposta aos questionários; b Percentagem global de resposta aos inquéritos administrados.

Quando interpelados a posicionarem-se sobre a escola que frequentam, constatou-se uma relativa convergência representacional em ambos os grupos de alunos inquiridos (excelentes e não excelentes), apenas tendo sido aferidas diferenças significativas em relação às opções político-organizacionais: de um lado, os alunos excelentes a reconhecerem a importância da escola na preparação para o ensino superior e na seleção dos alunos pelos resultados; de outro lado, os alunos não excelentes a valorizarem o papel da escola na preparação para o mercado de trabalho e a rejeitarem o critério seletivo para a admissão 
de novos alunos na escola (cf. Torres, 2015). Mas quando se mobiliza a variável escola para a análise das perspetivas dos alunos, de imediato sobressaem as diferenças representacionais, fazendo emergir a importância dos diferentes contextos na socialização dos jovens-alunos. Os 14 enunciados colocados à apreciação dos estudantes obtiveram níveis de concordância diferenciados consoante a escola de pertença, sendo possível encontrar perfis mais ou menos próximos dos dois cenários traçados na gráfico 1.

Os dados ilustrados na figura 4 mostram, comparativamente, a distribuição dos posicionamentos dos inquiridos em função da escola que frequentam, sendo possível identificar as diferenças em relação às dimensões políticas, organizacionais e pedagógicas. Se, numa primeira leitura, é possível visualizar uma distribuição uniforme expressa por uma certa sincronia das linhas que tecem a teia, um olhar mais detalhado e circunscrito a determinados enunciados revela diferenças significativas entre escolas. Nos EC1 e EC2 os alunos reconhecem a «boa organização» da escola e a sua vocação primeira para preparar os alunos para o ensino superior, considerando ainda serem estas escolas as melhores da região. De notar que, apesar das similitudes entre estas duas escolas, os alunos da EC1 conferem maior importância à liderança do Diretor, assim como tendem a reconhecer que a sua escola incentiva a competição entre alunos e turmas. Para além disso, esta escola diferencia-se de todas as outras ao ver reforçada a concordância com o enunciado «Nesta escola o importante é transmitir conteúdos e cumprir os programas». Como já se referiu atrás, esta constatação está em sintonia com o programa de ação do Diretor que, ao longo das últimas duas décadas, procurou manter o ethos de excelência escolar reconhecido na região.

A escola analisada no EC3, embora não muito distante do perfil das anteriores escolas, apresenta algumas especificidades, desde logo ao ver reconhecida pelos alunos a sua missão inclusiva e igualizadora. Embora reconheçam a «boa organização da escola», o maior consenso foi para a confirmação de que «Todos os alunos desta escola, independentemente das origens sociais, têm iguais oportunidades de sucesso» (média $=4,3$ ), associado ao facto de «No dia a dia desta escola [se promover] a aprendizagem da democracia e da cidadania» (média =4,19). Paralelamente à valorização das dimensões democráticas, os estudantes apontam como traço cultural desta escola um ambiente de trabalho propiciador do estudo e da qualidade das aprendizagens, associado ao estilo de liderança adotado pelo Diretor.

\section{Gráfico 4. Representações dos alunos em relação à organização escolar}

\section{(1 Discordância total; 5 Concordância total)}

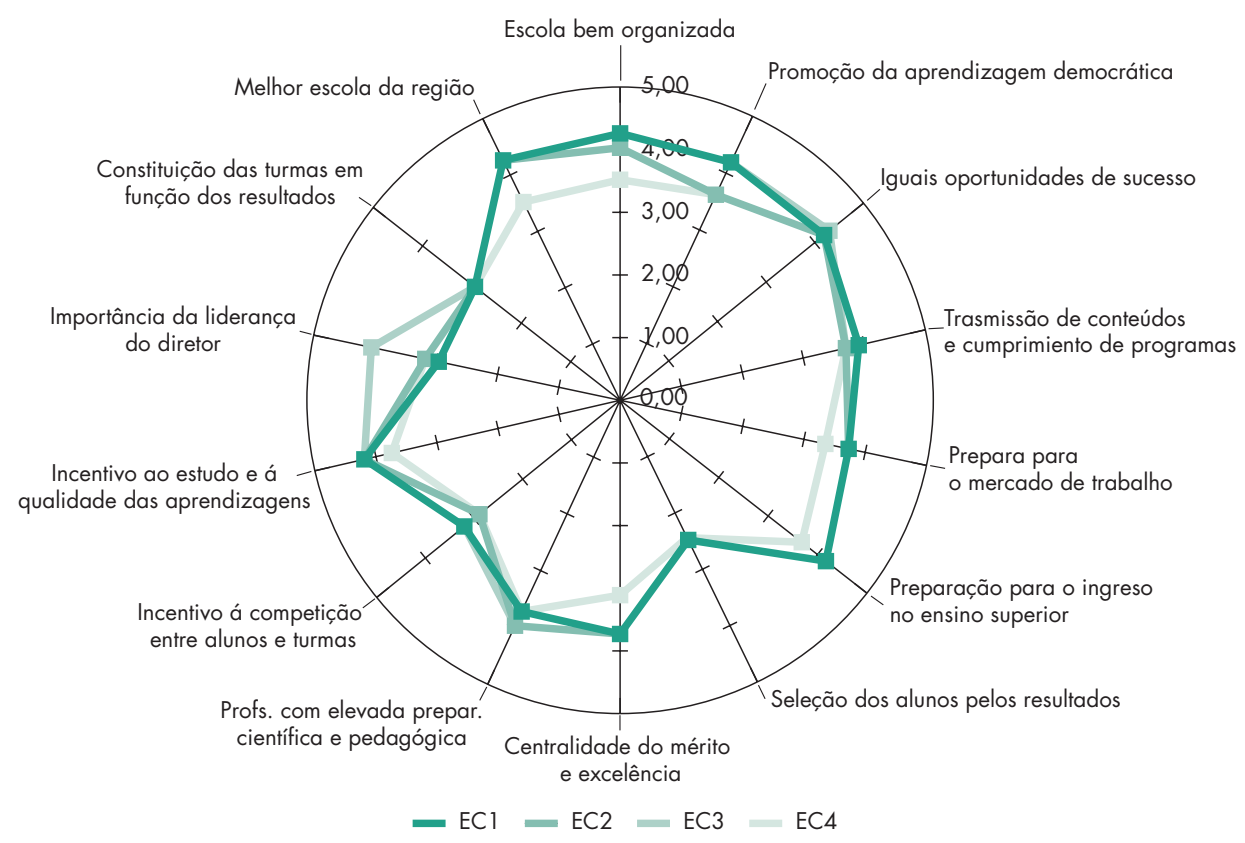


Por fim, o EC4 configura claramente uma escola com um perfil distinto das demais, cujos traços são visíveis na disposição da teia apresentada na gráfico 4. Para além de os valores de concordância estarem mais próximos do eixo central, evidenciando uma posição genericamente mais crítica dos alunos, verifica-se um menor reconhecimento das dimensões meritocráticas da escola, fazendo valer, em contraposição, a sua vocação inclusiva e democrática, a par do reconhecimento de um ambiente escolar propício ao estudo. Confirma-se, efetivamente, pelas respostas dos estudantes, que a escola não se enquadra num perfil elitista, pautando a sua atuação por princípios mais integradores e inclusivos.

\section{As perceções dos alunos em relação ao desempenho académico}

Procurando indagar os fatores que mais influenciam o desempenho académico dos alunos, submetemos à sua apreciação um conjunto de enunciados sobre vários aspetos, internos e externos à organização escolar, entre eles, o estilo de liderança do Diretor. Numa primeira análise global, os resultados apontam para a valorização das dimensões intra-escolares e, num segundo plano, para as dimensões individuais reportadas ao esforço e dedicação aos estudos. Com o objetivo de captar as diferenças significativas entre os vários estudos de caso, recorreu-se ao Teste de Kruskal-Wallis, cujos valores se assinalam no tabela 3. Os resultados apontam para diferenças consideráveis entre as várias escolas aos níveis organizacional, pedagógico, social e pessoal. Todavia, é de realçar que a significância estatística mais consistente $\left({ }^{* *} p<.001\right)$ se verifica na importância conferida pelos alunos ao «estilo de direção e gestão da escola». Por exemplo, no EC1 a organização e a liderança constituem as dimensões mais destacadas, indo de encontro ao seu ideário pedagógico focado na produção de resultados. Por sua vez, o esforço individual dos alunos e o clima pedagógico da escola parecem ser dimensões particularmente relevantes para o EC3.

Tabela III. Aspetos que contribuem para a promoção da excelência (1 Nada importante; 5 Muito importante)

\begin{tabular}{|c|c|c|c|c|c|}
\hline & $\begin{array}{c}\text { ECl } \\
\text { MEDIA }\end{array}$ & $\begin{array}{c}\text { EC2 } \\
\text { MÉDIA }\end{array}$ & $\begin{array}{c}\text { EC3 } \\
\text { MÉDIA }\end{array}$ & $\begin{array}{c}\text { EC4 } \\
\text { MÉDIA }\end{array}$ & $X^{2}(3)$ \\
\hline A qualidade dos professores(as) & 4,64 & 4,56 & 4,63 & 4,53 & 3,92 \\
\hline 0 clima pedagógico da escola & 4,34 & 4,24 & 4,44 & 4,36 & $\begin{array}{c}9,09 \\
\star\end{array}$ \\
\hline As origens sociais e culturais dos alunos(as) & 2,47 & 2,28 & 2,54 & 2,25 & $\begin{array}{c}7,04 \\
+ \\
\end{array}$ \\
\hline A composiçã̃o da turma & 3,68 & 3,59 & 3,81 & 3,77 & 5,76 \\
\hline A organização da escola & 4,21 & 4,06 & 4,23 & 4,18 & $\begin{array}{c}9,59 \\
*\end{array}$ \\
\hline 0 estilo de direção e gestĩo da escola & 4,06 & 3,87 & 4,20 & 4,02 & $\begin{array}{c}19,94 \\
\star \star \star\end{array}$ \\
\hline As características intelectuais dos alunos(as) & 3,63 & 3,42 & 3,50 & 3,47 & $\begin{array}{c}10,82 \\
*\end{array}$ \\
\hline As condições físicas e materiais da escola & 4,01 & 3,91 & 3,85 & 3,76 & $\begin{array}{c}9,86 \\
*\end{array}$ \\
\hline 0 projeto educativo da escola & 4,12 & 4,06 & 3,95 & 4,08 & $\begin{array}{c}6,29 \\
+\end{array}$ \\
\hline 0 envolvimento dos pais/encarregados de educacạ̃o & 3,57 & 3,51 & 3,82 & 3,50 & $\begin{array}{c}10,01 \\
* \\
\end{array}$ \\
\hline A participação em clubes, projetos e atividades extracurriculares (na escola) & 3,25 & 3,14 & 3,16 & 3,30 & 2,37 \\
\hline 0 esforço e a dedicacẵa individual do aluno(a) no estudo e nas aulas & 3,51 & 4,35 & 4,44 & 4,35 & $\underset{\star \star}{11,83}$ \\
\hline
\end{tabular}


Culturas de escola e excelência: entre a integração de todos e a distinção dos melhores

\begin{tabular}{lccccc}
\hline & $\begin{array}{c}\text { EC1 } \\
\text { MEDIA }\end{array}$ & $\begin{array}{c}\text { EC2 } \\
\text { MÉDIA }\end{array}$ & $\begin{array}{c}\text { EC3 } \\
\text { MÉDIA }\end{array}$ & $\begin{array}{c}\text { EC4 } \\
\text { MÉDIA }\end{array}$ & X $^{2}$ (3) \\
\hline O apoio ao estudo em explicaç̃oes e centros de estudo (fora da escola) & 3,31 & 3,21 & 3,09 & 3,19 & 5,27 \\
\hline O envolvimento dos alunos em atividades fora da escola (desporto, música ...) & 3,55 & 3,45 & 3,54 & 3,48 & 1,07 \\
\hline
\end{tabular}

${ }^{\dagger} p<.10 ;{ }^{*} p<.05 ; * * p<.01 ; * * *<.001$

Observação: optou-se por indicar a média para cada proposição, não apresentando senão neste quadro o valor do Teste de Kruskal-Wallis (Chi-Square), os graus de liberdade (3) e o nível de significância (Asymp. Sig).

As visões dos alunos em relação ao desempenho académico foram igualmente expressas em contexto de entrevista individual e coletiva. Os relatos detalhados sobre a organização e método do estudo mostram a importância da família e da escola na génese e reforço das disposições mais individualistas, focadas no esforço e na dedicação ao estudo. Efetivamente, quando convidados a refletir sobre o papel das condições sociofamiliares na aquisição de hábitos de estudo, os estudantes realçam as suas propriedades de reforço e antecipação das lógicas escolares:

«Em primeiro lugar temos que ser nós próprios, depois em segundo lugar eu não sei dizer [...] ou não sei propriamente por isto em lista, mas sei que o ambiente familiar é determinante porque eu tenho contato com colegas que muito provavelmente conseguiam ter muito melhores notas do que eu, mas que por terem um ambiente familiar que não é tão propicio a isso, não foram habituados a estudar». (Testemunho de uma aluna excelente).

«E precisamos de estabilidade familiar, é o ponto n. ${ }^{\circ}$ 1. Para mim -pode ser um cliché, uma frase feita, mas é verdade para mim - 'a família é tudo'. Se tivermos um acompanbamento da família desde o inicio, desde a primária, desde o infantário, os estímulos adequados a trabalhar, eu acho que as pessoas ganham hábitos de trabalho que depois não esquecem e continuam com esses hábitos de trabalho. A familia é importante nesse sentido de estimular principalmente numas fases mais precoces a ganharmos bábitos de trabalho e de estudo; depois também é preciso estabilidade familiar, porque se não tivermos estabilidade familiar não nos conseguimos concentrar. [...] Por exemplo, o meu pai quando eu andava no básico ajudava-me a matemática e estava comigo ao meu lado, lá está, os estímulos e a minha mãe também, como é professora primária acompanhou-me, mas foi especialmente a minha avó, porque eu ia à tarde para a minha avó, sempre me acompanhou nos trabalhos de casa, nos deveres, sempre me acompanhou nesse sentido». (Testemunho de uma aluna excelente).

O desenvolvimento de traços disposicionais favoráveis ao estudo parece ocorrer precocemente no seio familiar, sendo desde cedo reforçado na escola por via de uma intensa inculcação simbólico-ideológica, o que contribui para sedimentar uma forte propensão para o estudo. Esta característica é particularmente vincada nos alunos da EC3, na medida em que nesta organização se fomenta o desenvolvimento de métodos de estudo na escola e na própria família.

\section{Perceções dos alunos sobre a liderança}

As entrevistas individuais e em grupo realizadas a cerca de quatro dezenas de alunos foram muito ricas em informação acerca das representações em torno da figura do Diretor, relevando o seu papel na consolidação da imagem da instituição:

«- Toda a gente me dir. que ela é muito acessivivel, muito simpática, está sempre com um sorriso na cara, ela passa por nós nos corredores sorri sempre. 
- Mas é uma diretora presente, que acompanha.

- Acho que a diretora da escola se preocupa com os alunos, com os problemas, por exemplo, no dia 20 de fevereiro, que foi greve, a própria diretora estava ali a ver, a orientar tudo para ver se havia condições de segurança para haver aulas.

- Ela tem estado a fazer um bom trabalho na escola, pelo menos do que eu sinto.

- Uma pessoa séria e trabalhadora». (Depoimentos de alunos em entrevistas individuais, EC2).

No EC1 vários foram os testemunhos que puserem em evidência uma certa admiração pelo líder, ora induzida pela relação de proximidade e familiaridade desenvolvida ao longo do ano, ora sustentada em práticas regulares supostamente marcantes do ponto de vista da socialização escolar, como é o exemplo da sua deslocação a cada turma em particular para dar as boas-vindas à escola:

«- Dar um bom exemplo do que será um bom diretor é diz̧er que ele vai todos os dias almoçar à cantina e come exatamente a mesma coisa que os alunos

- Acho que é um bom diretor da escola, acho que é muito próximo dos alunos, ele até faz como os outros professores, come na cantina [risos], dir olá aos alunos, acho que é muito sociável e não tenho visto muitos problemas que tenham complicado a escola, isto é, porque ele os resolve bem, logo é um bom diretor.

- Mostra um bocado da sua preocupação com os alunos que são novos na escola. Ele todos os anos tem aquela preocupação de ir às salas dar as boas vindas aos alunos, não sei se nas outras escolas fazem isso. Mas ele todos os anos no primeiro periodo vai sempre aos alunos de $10 .^{\circ}$ ano dar as boas vindas à escola.

- Eu lembro-me que numa das primeiras aulas do $100^{\circ}$ ano ele foi a cada turma e tentou aproximar-se dos alunos e tentou dizer: 'olhem sintam-se confortáveis na escola e bom trabalho'». (Depoimentos de alunos em focus group, EC1).

Na EC3 a estratégia de liderança do Diretor assenta, igualmente, na criação de uma «relação autêntica», na aceção de Day, Harris, Hadfield, Tolley e Beresford (2000, p. 118), ancorada no desenvolvimento de um vínculo emocional propiciado pela proximidade, informalidade e sintonia com as preocupações dos estudantes:

«- Eu gosto muito deste diretor aqui porque ele sabe o nome de quase todos os alunos e interage muito com eles e anda sempre aqui à volta [...] anda sempre por aí, enquanto na outra escola em que andava, eu acho que só vi o diretor uma vez. e acho que um diretor tem que ter essas características que este diretor aqui tem.

- Um bom diretor é aquele diretor que desce de lá de cima, que aqui não é no primeiro andar, mas que desce do seu gabinete e vem interagir com os alunos e vê o que é que eles precisam e tanta ajudá- los o máximo que puder, como é o caso do nosso, que nos ajuda sempre que é preciso alguma coisa falamos com ele e ele ajuda-nos, está sempre disponivel, até nos dá sugestões para melhorarmos os nossos temas, está sempre aberto a novas opiniões e, pronto, que nos ajuda e acima de tudo que sabemos que podemos contar com ele.

- Eu estou aqui há pouco tempo, ainda só entrei este ano, mas já deu para perceber que é uma pessoa impecável, fui bem-recebido, na apresentação veio logo ter comigo. Fiquei assim um bocado chocado, mas pronto, de vez. em quando está ali à porta da entrada das manhãs a dizer bom dia a toda a gente, é uma pessoa impecável e pronto um bom diretor tem que ajudar os alunos, incentivá-los, apoiá-los e fazer sugestões para que melhoremos». (Depoimentos de alunos em focus group, EC3). 
Por fim, na EC4 enaltece-se, de forma entusiástica, a capacidade integradora da direção, sempre preocupada com a participação de todos os atores educativos, bem como o fomento de um «bom ambiente» facilitador das relações interpessoais e da aprendizagem:

«-Sim! Eles tentam sempre envolver os pais em todas as festas que haja na escola

- Acredito que a Direção faz os possiveis e trabalha de uma maneira que possa ajudar toda a gente... os alunos, os professores, os não docentes, tudo!

- Eu se calhar estou um pouco mais por dentro, porque já fui um ponco ajudado pela Direção. Acho que a Direção desta escola é fantástica mesmo a nivel de ajudar os alunos, tentar envolver todas as pessoas, dos profissionais aos pais, tentam informar as pessoas... tentar chegar ao consenso entre todos e fazer com que todos estejam bem, bem integrados e felizes e acho que sim, que a Direção faz um bom trabalho.

- Consegue-se apontar que a Direção está lá para toda a gente.

- Acho que a escola também se adapta um bocadinho às nossas opiniões e acho que é bem gerida. Acho que existe uma boa relação entre alunos e professores [...] também acho que bá uma muito boa relação entre alunos e funcionários. Eu também trato todos os funcionários que eu conbeģo pelo nome, acho que não tenho nenhum problema». (Depoimentos de alunos em focus group, EC4).

Os relatos dos alunos expressam diferentes estilos de liderança, claramente alinhados com as respetivas culturas de escola: na EC1 e na EC2 destaca-se um estilo focado no desenvolvimento de uma ética de trabalho assente no esforço, na dedicação e na performance individual; na EC3, um estilo mais pedagógico, empático e de grande proximidade dos alunos; na EC4 exalta-se a promoção de uma ampla participação dos atores na vida da escola e o investimento na criação de um ambiente favorável ao trabalho e ao estudo.

\section{Considerações finais}

Ao longo deste artigo procurou-se refletir sobre a importância dos fatores culturais na construção dos resultados escolares, sem, no entanto, perder de vista a multidimensionalidade inerente a esta temática. O exercício analítico passou, portanto, por focar o olhar sobre as dimensões intra-escola, designadamente os efeitos da cultura de escola (nas suas diferentes facetas) na reconfiguração dos processos de liderança e no condicionamento dos percursos de socialização dos estudantes. Optou-se por uma linha de pesquisa reflexiva, focada essencialmente na compreensão dos processos de construção de habitus (no sentido de Bourdieu) e de sistemas de disposições (na ótica de Lahire), estruturadores da cultura organizacional de escola. Esta matriz cultural e simbólica, diferentemente construída em cada escola observada, afigurou-se, nesta abordagem, um importante espaço-tempo de socialização dos jovens estudantes, possibilitando uma mais sólida apreensão das suas representações e sentidos conferidos às práticas de escolarização.

Os resultados de investigação aqui parcelarmente debatidos vêm reforçar a relevância do efeito-escola no desenvolvimento de figurinos organizacionais, na definição de estilos e padrões de liderança e no modo como o programa de socialização institucional (Dubet, 2002) condiciona as representações dos alunos. Com efeito, as especificidades culturais das escolas não só induzem determinados estilos de liderança, conferindo-lhes sentido e legitimidade política, como se deixam reconfigurar pelas suas dinâmicas quotidianas. Os alunos, enquanto atores em processo de socialização, incorporam certos padrões de funcionamento, traduzidos em arranjos organizacionais, registados na memória como marcadores simbólicos que 
passam a modelar os seus comportamentos e expectativas face à escola. Prova disto mesmo, os quatro estudos de caso revelaram diferenças significativas no modo como os alunos percecionavam a organização da sua escola e a sua importância no desenvolvimento do ideário da excelência. Mais ainda, a relação entre a qualidade da escola e o estilo de liderança adotado pelo Diretor foi o enunciado que mais acentuou as diferenças inter-escolas.

Não sendo indiferentes às dimensões político-organizacionais, pelo contrário, os alunos parecem interiorizar de forma significativa a cultura de escola, ao ponto de atribuir centralidade aos fatores organizacionais na construção da excelência académica. $\mathrm{O}$ facto de relegarem para segundo plano as dimensões externas (condição sociocultural das famílias) pode ser um indicador dos efeitos da sua longa socialização na instituição escolar e do lugar central que este contexto ocupa no desenvolvimento de disposições face à escola. Como diretos «beneficiários» das orientações das lideranças escolares, os estudantes enunciam pontos de vista do lado de quem tem de dar forma aos resultados e, em última instância, dão expressividade à ação bem ou malsucedida das lideranças.

Embora a proposta teórica apresentada neste artigo se revele heuristicamente pertinente no aprofundamento das abordagens culturais, a sua operacionalização metodológica desafia os paradigmas convencionais de investigação, exigindo a deslocação da escala de observação para um ponto intermédio que permita captar as singularidades plurais dos atores, tendo como referência os contextos de socialização, sobretudo aqueles que mais exercem um efeito durável, como é o caso da escola. Mais do que o ator, o decurso da ação adquire centralidade analítica, exigindo do investigador uma constante deambulação entre enfoques, numa tentativa de imersão nos processos de subjetivação inerentes aos diversos nichos de socialização. $\mathrm{O}$ estudo aqui apresentado constitui apenas um primeiro passo de aproximação a este desafio, a aguardar novas investidas em trabalhos próximos.

\section{Referências bibliográficas}

Alvesson, Mats (2002). Understanding Organizational Culture. London: Sage Publications.

Barzanò, Giovanna (2009). Culturas de liderança e lógicas de responsabilidade. As experiências de Inglaterra, Itália e Portugal. Vila Nova de Gaia: Fundação Manuel Leão.

Bourdieu, Pierre (1997). Rąões Práticas. Sobre a Teoria da Acção. Oeiras: Celta Editora (1. a edição original em 1994).

Bourdieu, Pierre (2002). Esboço de uma Teoria da Prática. Precedido de Três Estudos de Etnologia Cabila. Oeiras: Celta Editora (1. a edição original em 1972).

Day, Christopher; Harris, Alma Hadfield, Mark; Tolley, Harry, e Beresford, John (2000). Leading Schools in Times of Change. Buckingham: Open University Press.

Derouet, Jean-Louis e Normand, Romuald (Dir.) (2014). La question du leadership en éducation. Perspectives européennes. Louvain-la-Neuve: Academia-L'Harmattan S.A.

Du Gay, Paul (2007). Organizing Identity. London: Sage Publications.

Dubet, François (2002). Le déclin de l'institution. Paris : Éditions du Seuil.

Frost, Peter J.; Moore, Larry F.; Louis, Meryl R.; Lundberg, Craig C. e Martin, Joanne (Eds.). (1991). Reframing Organizational Culture. London: Sage Publications. 
Hargreaves, Andy; Boyle, Alan e Harris, Alma (2014). Uplifting leadership: How Organizations, Teams, and Communities Raise Performance. San Francisco: Jossey-Bass.

Hargreaves, David (1995): “School Culture, School Effectiveness and School Improvement". School Effectiveness and School Improvement, 6 (1), 23-46.

Lahire, Bernard (2003). O homem plural. As molas da ação. Lisboa: Instituto Piaget.

Lahire, Bernard (2004). Retratos sociológicos. Disposições e variações individuais. Porto Alegre: Artmed.

Lima, Licínio C. (2012): "Elementos de hiperburocratização da administração educacional” em Carlos Lucena e João R. Júnior (Orgs.): Trabalho e Educação no Século XXI. Experiências Internacionais. São Paulo: Xamã.

Lindle, Jane C. (Ed.). (2014). Political Contexts of Educational Leadership. New York: Routledge.

Martin, Joanne (1992). Cultures in Organizations. Three Perspectives. New York, Oxford: Oxford University Press. London: Sage Publications.

Martin, Joanne (2002). Organizational Culture. Mapping the Terrain. London: Sage Publications.

Pérez Gómez, Ángel I. (1998). La cultura escolar en la sociedad neoliberal. Madrid: Ediciones Morata.

Power, Sally \& Whitty, Geoff (1999): "Market Forces and School Cultures” em Jon Prosser (Ed.): School Culture. London: Sage Publications.

Prosser, Jon (1999): “The Evolution of School Culture Research" em Jon Prosser (Ed.): School Culture. London: Sage Publications.

Schein, Edgar H. (1985). Organizational Culture and Leadership. São Francisco: Jossey-Bass Publishers.

Sergiovanni, Thomas (2004). O mundo da liderança. Desenvolver culturas, práticas e responsabilidade pessoal nas escolas. Porto: Edições ASA.

Teixeira, Lúcia H. (2002). Cultura organizacional e projeto de mudança em escolas públicas. Campinas: Editora Autores Associados.

Torres, Leonor L. (1997). Cultura organizacional escolar. Representações dos professores numa escola portuguesa. Oeiras: Celta Editora.

Torres, Leonor L. (2004). Cultura organizacional em contexto educativo. Sedimentos culturais e processos de construção do simbólico numa escola secundária. Braga: Centro de Investigação em Educação da Universidade do Minho.

Torres, Leonor L. e Palhares, José A. (2015): “Cultura, liderança e resultados escolares: uma abordagem a partir das representações dos alunos do ensino secundário”. Revista Lusófona de Educação, 30, 99-121.

Torres, Leonor L. (2010): “Cultura organizacional em contexto escolar” em Licínio C. Lima (Org.): Perspectivas de Análise Organizacional das Escolas. Vila Nova de Gaia: Fundação Manuel Leão.

Torres, Leonor L. (2017): “Cultura organizacional de escola, liderança e produção de resultados” em Leonor L. Torres \& José A. Palhares (Orgs.): A excelência académica na escola pública portuguesa. Vila Nova de Gaia: Fundação Manuel Leão. 


\section{Nota biográfica}

Leonor L. Torres é socióloga, professora associada do Instituto de Educação da Universidade do Minho (Braga, Portugal) e investigora do Centro de Investigação em Educação (CIEd) da mesma Universidade. Integra a coordenação da Secção de Sociologia da Educação da Associação Portuguesa de Sociologia (APS) desde 2014. Tem investigado no domínio da sociologia das organizações educativas, privilegiando os temas da cultura organizacional, liderança escolar e percursos de excelência. 